\title{
Ultraviolet actinic flux in clear and cloudy atmospheres: model calculations and aircraft-based measurements
}

\author{
G. G. Palancar ${ }^{1,2}$, R. E. Shetter ${ }^{2}$, S. R. Hall ${ }^{2}$, B. M. Toselli ${ }^{1}$, and S. Madronich ${ }^{2}$ \\ ${ }^{1}$ INFIQC-CONICET, Departamento de Físico Química, Facultad de Ciencias Químicas, Universidad Nacional de Córdoba, \\ Centro Láser de Ciencias Moleculares, 5000, Córdoba, Argentina \\ ${ }^{2}$ Atmospheric Chemistry Division, National Center for Atmospheric Research, Boulder, Colorado, USA
}

Received: 29 December 2010 - Published in Atmos. Chem. Phys. Discuss.: 31 January 2011

Revised: 23 May 2011 - Accepted: 27 May 2011 - Published: 14 June 2011

\begin{abstract}
Ultraviolet (UV) actinic fluxes measured with two Scanning Actinic Flux Spectroradiometers (SAFS) aboard the NASA DC-8 aircraft are compared with the Tropospheric Ultraviolet-Visible (TUV) model. The observations from 17 days in July-August 2004 (INTEX-NA field campaign) span a wide range of latitudes $\left(28^{\circ} \mathrm{N}-53^{\circ} \mathrm{N}\right)$, longitudes $\left(45^{\circ} \mathrm{W}-140^{\circ} \mathrm{W}\right)$, altitudes $(0.1-11.9 \mathrm{~km})$, ozone columns $(285-353 \mathrm{DU})$, and solar zenith angles $\left(2^{\circ}-85^{\circ}\right)$. Both cloudy and cloud-free conditions were encountered. For cloud-free conditions, the ratio of observed to clearsky-model actinic flux (integrated from 298 to $422 \mathrm{~nm}$ ) was $1.01 \pm 0.04$, i.e. in good agreement with observations. The agreement improved to $1.00 \pm 0.03$ for the down-welling component under clear sky conditions. In the presence of clouds and depending on their position relative to the aircraft, the up-welling component was frequently enhanced (by as much as a factor of 8 relative to cloud-free values) while the down-welling component showed both reductions and enhancements of up to a few tens of percent. Including all conditions, the ratio of the observed actinic flux to the cloud-free model value was $1.1 \pm 0.3$ for the total, or separately $1.0 \pm 0.2$ for the down-welling and $1.5 \pm 0.8$ for the up-welling components. The correlations between up-welling and downwelling deviations are well reproduced with sensitivity studies using the TUV model, and are understood qualitatively with a simple conceptual model. This analysis of actinic flux observations illustrates opportunities for future evaluations of photolysis rates in three-dimensional chemistry-transport models.
\end{abstract}

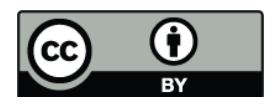

Correspondence to: G. G. Palancar (palancar@fcq.unc.edu.ar)

\section{Introduction}

Solar ultraviolet (UV) radiation initiates much of the chemistry of Earth's troposphere by photo-dissociating relatively stable molecules into highly reactive fragments such as oxygen atoms and hydroxyl or organic radicals. The subsequent reactions of these photo-fragments determine the atmospheric lifetimes of numerous compounds including hydrocarbons, nitrogen oxides, sulfur dioxide, and many organohalogens, and are essential to the formation of tropospheric oxidants and secondary aerosols (nitrate, sulfate, and organic). The rate coefficient for photo-dissociation $J$ is given by

$J=\int F(\lambda) \sigma(\lambda) \varphi(\lambda) d \lambda$

where $F(\lambda)$ is the spectral actinic flux (fluence rate) at wavelength $\lambda, \sigma(\lambda)$ is the absorption cross section of the target molecule, and $\varphi(\lambda)$ is the quantum yield of specific photoproducts. The actinic flux includes the radiance $L(\lambda, \theta, \phi)$ from all angular directions $\theta, \phi$ :

$F(\lambda)=\iint L(\lambda, \theta, \phi) \sin \theta d \theta d \phi$

although in practice a distinction is often made for the contributions of the direct solar beam $\left(F^{o}\right)$, and the diffuse radiation down-welling $\left(F^{\downarrow}\right)$ and up-welling $\left(F^{\uparrow}\right)$ incident respectively from the upper and lower hemispheres. This diffuse radiation arises from molecular (Rayleigh) scattering which is particularly effective at UV wavelengths due to its $\lambda^{-4}$ dependence, from reflections at the Earth's surface (the albedo of land or water), and from scattering by aerosols and clouds. The calculation of actinic fluxes is a critical component of chemistry-transport models (CTMs) used to study environmental problems such as photochemical smog, regional

Published by Copernicus Publications on behalf of the European Geosciences Union. 
oxidants, acid precipitation, and chemistry-climate interactions.

For cloud-free conditions, the calculation of the actinic flux with radiative transfer models is relatively straightforward (e.g. Turco, 1975; Meier et al., 1997) and is generally in good agreement with observations. During the International Photolysis Measurement and Model Intercomparison (Bais et al., 2003) spectroscopic, radiometric, and actinometric measurements were made at the surface under cloud-free skies and compared with 16 models, of which the majority (11) agreed within $\pm 6 \%$ for solar zenith angles smaller than $\sim 60^{\circ}$. Clear-sky model predictions also work well aloft, where observations have been made from a number of different platforms including stratospheric balloons (Madronich et al., 1985), hang-gliders (Junkermann, 1994), tethered balloons (Vilà-Guerau de Arellano et al., 1994; de Roode et al., 2001), and fixed-wing aircraft (Kelley et al., 1995; VolzThomas et al., 1996; Shetter and Müller, 1999; Crawford et al., 1999; Jäkel et al., 2005; Kylling et al., 2005).

Cloudy conditions, on the other hand, have been problematic for both the modeling and the observation of actinic flux. The difficulties arise from two general issues: (1) Clouds exhibit complex morphologies and optical properties that are highly variable in space and time; the representation of clouds in models is at best only an approximation to real clouds. (2) Even for specifically defined model cloud fields, radiative transfer models often make additional approximations to achieve manageable computational efficiency, e.g. assuming homogeneous cloudiness horizontally (reducing the problem from three dimensions to one), vertical discretization into uniform layers, and analytic approximations of the scattering phase functions. Actinic flux measurements confirm the high variability in the presence of clouds (Junkermann, 1994; Pfister et al., 2000; Lefer et al., 2003; Shetter et al., 2003; Thiel et al., 2008) but in most cases the detailed information needed as input to radiative transfer models is not available.

Clouds generally reduce the actinic flux reaching Earth's surface, although temporary or local enhancements can occur with broken clouds that, as is often the case, appear brighter than the blue sky sector they obscure (Lantz et al., 1996; Crawford et al., 2003). At high altitudes above the clouds, actinic fluxes are generally enhanced by the strong up-welling radiation component from cloud reflections, and within clouds both increases and decreases of actinic fluxes can occur. Several radiative transfer models have been developed to describe the effects of clouds on actinic fluxes (Madronich, 1987; Jacob et al, 1989; van Weele and Duynkerke, 1993; Los et al., 1997; Trautmann et al., 1999; Brasseur et al., 2002; Mayer and Kylling, 2005). Cloudysky evaluations of the radiative transfer models with observations have been sparse because of the need for simultaneous measurements of actinic fluxes and cloud properties, as mentioned above. In the few cases where some cloud parameters (e.g. liquid water content) were available, the ob- servations generally confirm the radiative model predictions (Vilà-Guerau de Arellano et al., 1994; de Roode et al., 2001; Kylling et al., 2005; Thiel et al., 2008).

Three-dimensional CTMs typically use pre-tabulated clear-sky values with on-line correction for cloud effects above, inside, and below clouds (e.g., Chang et al, 1987), or more recently on-line radiative calculations at reduced number of wavelengths (Landgraf and Crutzen, 1998; Wild et al., 2000; Tie et al., 2003). The importance of cloud-modified photolysis reactions to predicting tropospheric composition is now well recognized (e.g., Chang et al., 1987; Lelieveld and Crutzen, 1990; Tie et al., 2003; Lefer et al., 2003; Liu et al., 2006; Voulgarakis et al., 2009). Radiative transfer approximations are only part of the uncertainty, with a large contribution stemming from how the clouds themselves are represented in the models. For example, Pour-Biazar et al. (2007) found increased skill in predicting surface ozone concentrations when, for the purpose of computing photolysis rates, model-generated clouds were replaced by satelliteobserved clouds. Despite such importance, evaluation of actinic fluxes in CTMs is largely lacking, particularly for cloudy conditions and aloft. As observations become increasingly available, strategies will need to be developed on how to formulate the most useful model-observation comparisons.

In this study, we analyze the actinic flux measurements taken during the Intercontinental Chemical Transport Experiment - North America Phase A campaign, INTEX-NA 2004 (Singh et al., 2006) considering both cloud-free and cloudinfluenced conditions. Section 2 describes the measurement and modeling methods. Section 3 shows selected results with emphasis on the observed deviations from modeled cloudfree results, which are discussed further in Sect. 4. Some concluding perspectives are given in Sect. 5. Appendix A presents a simple analytic model to aid in the qualitative description and in the development of simple parameterizations of the cloud effects on actinic flux.

\section{Methods}

\subsection{Measurements}

All the measurements used in this work were taken during the INTEX-NA 2004 campaign with two Scanning Actinic Flux Spectroradiometers (SAFS) developed at the National Center for Atmospheric Research (NCAR, USA). Both instruments were installed on the NASA DC-8 research aircraft. A complete description of the instruments, calibration procedures and installation on the aircraft is given by Shetter and Müller (1999) and Shetter et al. (2003). In brief, the instrumentation consists of two identical spectroradiometers, each collecting radiation from one hemisphere $(2 \pi \mathrm{sr})$. The quartz optical collectors were equipped with artificial horizons to decrease their response to radiation out of the hemisphere 
being sampled. The gratings have a ruling of 2400 lines $/ \mathrm{mm}$ and the entrance and the exit slit widths are fixed to $0.6 \mathrm{~mm}$, resulting in a bandpass (FWHM) of $1.0 \mathrm{~nm}$. Each wavelength scan started at $282 \mathrm{~nm}$ and the monochromator was stepped in $1 \mathrm{~nm}$ intervals up to $422 \mathrm{~nm}$. The acquisition time for each $282-422 \mathrm{~nm}$ spectrum was about $9 \mathrm{~s}$. After a scan was finished, the instruments waited $0.5-1 \mathrm{~s}$ until the start of the next $10 \mathrm{~s}$ period. Time synchronization hardware and associated software enabled the separate zenith and nadir SAFS systems to be synchronized within $1 \mathrm{~ms}$ to assure simultaneous readings at each wavelength. The accuracy of the measurements is estimated to be $6 \%$ in the UV-B and 5\% in the visible (including drift during the campaign) while the optical angular responses of the instruments are $\pm 3 \%$ for solar zenith angles less than $80^{\circ}$.

The wavelengths between 282 and $288 \mathrm{~nm}$ are used to estimate the electronic background on a scan by scan basis, since no photons with wavelengths shorter than $290 \mathrm{~nm}$ penetrate the atmosphere to the altitude range of the DC-8. In addition, the signal from these wavelengths is used to determine the stray light contribution from visible wavelengths, and apply this correction to all wavelengths. Geographic and meteorological data collected on board the aircraft, or calculated through the measured data, consisted of altitude, latitude, longitude, time (UTC), and pressure and temperature at the flight altitude at every second.

During INTEX-NA (1 July to 14 August 2004) the NASA DC-8 aircraft performed eighteen flights over different surfaces (open sea, coast, large cities, meadows, mountains, etc.). Measurements from 28 July were not used due to lack of ozone data for that day. The original set with 50227 spectra was filtered to eliminate SZA larger than $85^{\circ}$ and cases where the aircraft pitch and roll angles exceed $\pm 5^{\circ}$. In the filtered data set (39336 spectra) latitude spans $28^{\circ} \mathrm{N}$ to $53^{\circ} \mathrm{N}$, longitude $140^{\circ} \mathrm{W}$ to $45^{\circ} \mathrm{W}$, surface elevation 0 to $3.3 \mathrm{~km}$ a.s.l., and flight altitude 0.1 to $11.9 \mathrm{~km}$ a.s.l. The ozone column values varied from 285 up to 353 Dobson Units and the SZA from $2^{\circ}$ to $81^{\circ}$.

\subsection{Radiative transfer model}

All calculations were carried out with the Tropospheric Ultraviolet-Visible (TUV) model (Madronich, 1987) developed at NCAR. In the present work, version 4.2 was adapted to use the aircraft data files as input parameters. The model considers the extraterrestrial solar spectral irradiance (Van Hoosier et al., 1987; Neckel and Labs, 1984) and computes its propagation through the atmosphere taking into account multiple scattering and absorption due to gases and particles. Both Rayleigh and Mie scattering are considered depending on particle size. The Earth atmosphere is divided in 80 equally spaced layers, each $1 \mathrm{~km}$ thick with homogeneous composition and properties according to the United States Standard Atmosphere (USSA, 1976) which considers an annual average ozone profile (for $45^{\circ} \mathrm{N}$ ) for $2-74 \mathrm{~km}$ al- titudes, while values at 0 and $1 \mathrm{~km}$ are filled in assuming a typical surface mixing ratio of $40 \mathrm{ppb}$. An 8-stream discrete ordinate method (Stamnes et al., 1988) was used for the calculations, with aerosol-free sky conditions. A pseudospherical correction was applied to account for Earth's curvature (Petropavlovskikh, 1995). The calculations were carried out at each wavelength from 298 to $422 \mathrm{~nm}$ with a resolution of $1 \mathrm{~nm}$ to match the resolution of the instruments. The surface albedo was assumed to be Lambertian and wavelengthindependent, with values of $5 \%$ over land and $10 \%$ over water (Madronich, 1993; Shetter et al., 2003). The components of the total actinic flux (i.e. direct, diffuse up-welling, and diffuse down-welling) were calculated separately to simulate the $2 \pi$ sr field of view of each spectroradiometer.

Surface elevation was taken from a global Digital Elevation Model (GTOPO30 data base, US Geological Survey's EROS Data Center; Jet Propulsion Laboratory, 1997) and bilinearly interpolated to follow the aircraft path. The meteorological and geographical data obtained along the aircraft flight path were averaged for each scan period and used as model inputs. Ozone data were taken from TOMS satellite archives (http://jwocky.gsfc.nasa.gov) and bilinearly interpolated to retrieve the actual value at the latitude and longitude of the aircraft flight path. Then, the USSA $\mathrm{O}_{3}$ profile was scaled to the obtained TOMS values. Most of the model calculations discussed below are for cloud-free conditions. Some additional sensitivity studies were made with model clouds of specified optical depth and vertical layering, assumed to be horizontally infinite with single scattering albedo 0.9999 and asymmetry factor 0.85 .

To simplify the analysis and presentation of these large data sets, we integrated both the modeled and measured spectra from 298 to $422 \mathrm{~nm}$, i.e. essentially over the ultraviolet part of the tropospheric spectrum, with a slight extension into the visible to encompass the longer-wavelength photolysis of nitrogen dioxide.

\section{Results}

\subsection{Illustrative flights - clear and cloudy}

The actinic fluxes observed and calculated for 13 August are shown in Fig. 1. The total actinic flux (Fig. 1a) shows good agreement during most of the $7 \mathrm{~h}$ flight (all times UTC) spanning a wide range of latitudes $\left(38^{\circ} \mathrm{N}-29^{\circ} \mathrm{N}\right)$, longitudes $\left(88^{\circ} \mathrm{W}-97^{\circ} \mathrm{W}\right)$, altitudes $(0.3-11.3 \mathrm{~km}$, shown in Fig. 1a), ozone column (292-344 DU), and solar zenith angles ( $24^{\circ}-$ $78^{\circ}$, shown in Fig. 1b). Examination of three cameras installed on board the DC-8 (nadir, zenith, and front) and flight track overlays on GOES-10 or GOES-12 imagery indicate that this day was mostly free of clouds, except for brief periods around 16:15 and 20:15 UTC. This is consistent with the good agreement between the modeled and observed downwelling flux (Fig. 1b), with observations in the second half 
Table 1. Average ratios of the integrated actinic fluxes $(298-422 \mathrm{~nm})$ measured to those calculated with the cloud-free model, for all INTEXNA flights.

\begin{tabular}{crcccc}
\hline Flight & Day (2004) & \multicolumn{3}{c}{ Average $\pm \sigma$} & Number of data \\
\hline & & Total & Downwelling & Upwelling & \\
3 & 1 July & $1.2 \pm 0.4$ & $1.0 \pm 0.2$ & $2 \pm 1$ & 2499 \\
4 & 6 July & $1.0 \pm 0.3$ & $0.9 \pm 0.2$ & $1.4 \pm 0.9$ & 2275 \\
5 & 8 July & $1.1 \pm 0.3$ & $1.0 \pm 0.1$ & $2 \pm 1$ & 2584 \\
6 & 10 July & $1.1 \pm 0.3$ & $1.0 \pm 0.3$ & $1.4 \pm 0.7$ & 2354 \\
7 & 12 July & $1.0 \pm 0.2$ & $1.0 \pm 0.2$ & $1.1 \pm 0.5$ & 2515 \\
8 & 15 July & $1.1 \pm 0.3$ & $1.0 \pm 0.2$ & $1.5 \pm 0.8$ & 1966 \\
9 & 18 July & $1.1 \pm 0.3$ & $0.9 \pm 0.2$ & $2 \pm 1$ & 2562 \\
10 & 20 July & $1.1 \pm 0.1$ & $1.0 \pm 0.1$ & $1.3 \pm 0.3$ & 1994 \\
11 & 22 July & $1.1 \pm 0.2$ & $1.00 \pm 0.08$ & $1.4 \pm 0.5$ & 1899 \\
12 & 25 July & $1.1 \pm 0.3$ & $1.0 \pm 0.2$ & $1.6 \pm 0.7$ & 2249 \\
14 & 31 July & $0.9 \pm 0.2$ & $0.9 \pm 0.2$ & $1.2 \pm 0.6$ & 2438 \\
15 & 2 August & $1.1 \pm 0.2$ & $1.0 \pm 0.1$ & $1.4 \pm 0.8$ & 2559 \\
16 & 6 August & $1.1 \pm 0.3$ & $1.0 \pm 0.2$ & $1.6 \pm 0.9$ & 2564 \\
17 & 7 August & $1.0 \pm 0.4$ & $0.9 \pm 0.3$ & $1.6 \pm 0.9$ & 2487 \\
18 & 11 August & $1.1 \pm 0.3$ & $1.0 \pm 0.2$ & $1.4 \pm 0.8$ & 2027 \\
19 & 13 August & $1.02 \pm 0.07$ & $0.99 \pm 0.05$ & $1.2 \pm 0.3$ & 2180 \\
20 & 14 August & $1.2 \pm 0.3$ & $1.0 \pm 0.2$ & $1.6 \pm 0.8$ & 2184 \\
\hline Cloud-free & & $1.01 \pm 0.04$ & $1.00 \pm 0.03$ & $1.1 \pm 0.2$ & 6844 \\
\hline All data & & $1.1 \pm 0.3$ & $1.0 \pm 0.2$ & $1.5 \pm 0.8$ & 39336 \\
\hline
\end{tabular}

of the flight slightly lower due possibly to the presence of aerosols which are not included in the model. The good agreement for up-welling radiation (also Fig. 1b) is notable, with both observations and model showing similar enhancements with altitude due to the increasing Rayleigh optical depth below the aircraft.

The flight of 7 August (Fig. 2) also shows characteristically cloud-free behavior during the first few hours, but after about 17:00 UTC entirely different patterns are observed. Compared to the cloud-free model, the observed total actinic flux is much smaller at low flight altitudes and much larger at high altitudes. The observed down-welling component has a similar pattern, although the high-altitude enhancements are not as large as for the total actinic flux. The up-welling actinic flux shows strong enhancements at high altitudes, and some reductions at the lowest altitudes. This behavior is obviously consistent with mid-level clouds and a flight path that alternates between being below and above clouds.

\subsection{All-flights statistics}

The cloud-induced effects from all flights are summarized in Table 1, expressed as averaged ratios of the observations to the cloud-free calculations, for the total actinic flux $\left(Q^{\text {tot }}\right)$ as well as separately for the up-welling and down-welling components, $Q^{\uparrow}$ and $Q^{\downarrow}$ respectively. The total actinic flux, averaged over each flight, agrees to about $10 \%$ for most flights, with observations usually exceeding the predictions of the cloud-free model. This is seen to result mainly from the up- welling component $Q^{\uparrow}$, which tends to be well above unity suggesting the frequent presence of clouds below the aircraft, while the down-welling component $Q^{\downarrow}$ is very close to unity on all days. When cloud-free observations are selected (penultimate row in Table 1), the agreements are much closer for both $Q^{\uparrow}$ and $Q^{\downarrow}$. In particular, $Q^{\downarrow} \sim 1.00 \pm 0.03$ is within the range expected from the absolute radiometric calibrations of the SAFS and of the extraterrestrial spectral irradiance used in the TUV model.

Figure 3 shows the frequency distribution of $Q^{\uparrow}$ and $Q^{\downarrow}$ for all flights, with orange bars showing all data and blue bars only the cloud-free subset. As already mentioned, the total actinic flux ratios are skewed towards values larger than 1 (average ratio $\sim 1.1 \pm 0.3$ for all data, $\sim 1.01 \pm 0.04$ for the cloud-free subset). For the down-welling actinic flux, $Q^{\downarrow}$ values lower than unity are common (attenuation by clouds), but so are enhancements of 10-20\% due to the radiance from the base of clouds above the aircraft. The up-welling radiation shows both reductions and enhancements, with the latter ratios $Q^{\uparrow}$ reaching rather high values, up to a factor of 8 presumably due to particularly bright low clouds. Thus, small enhancements of the total actinic flux (10-20\%) can be due to the higher down-welling component, but the larger enhancements (up to a factor of 2) can only be due to the reflections from cloud below the aircraft. 
Table 2. Typical sky conditions as seen from an aircraft.

\begin{tabular}{ccccccc}
\hline Case & Direct Sun & Clouds above & Clouds below & $Q^{\downarrow}$ & $Q^{\uparrow}$ & Comments \\
\hline 1 & yes & no & no & 1 & 1 & Clear sky $A=A_{O}$ \\
2 & yes & no & yes & $>1$ & $\gg 1$ & $A \gg A_{O}$ \\
3 & yes & broken & no & $>1$ & $<1$ & \\
4 & yes & broken & yes & $\gg 1$ & $\gg 1$ & $A \gg A_{O}$ \\
5 & no & broken & no & $<1$ & $<1$ & \\
6 & no & broken & yes & $<1$ & $>1$ & $A \gg A_{O}$ \\
7 & no & overcast & no & $\ll 1$ & $\ll 1$ & \\
8 & no & overcast & yes & $<1$ & $>1$ & Inside cloud $A \gg A_{O}$ \\
\hline
\end{tabular}

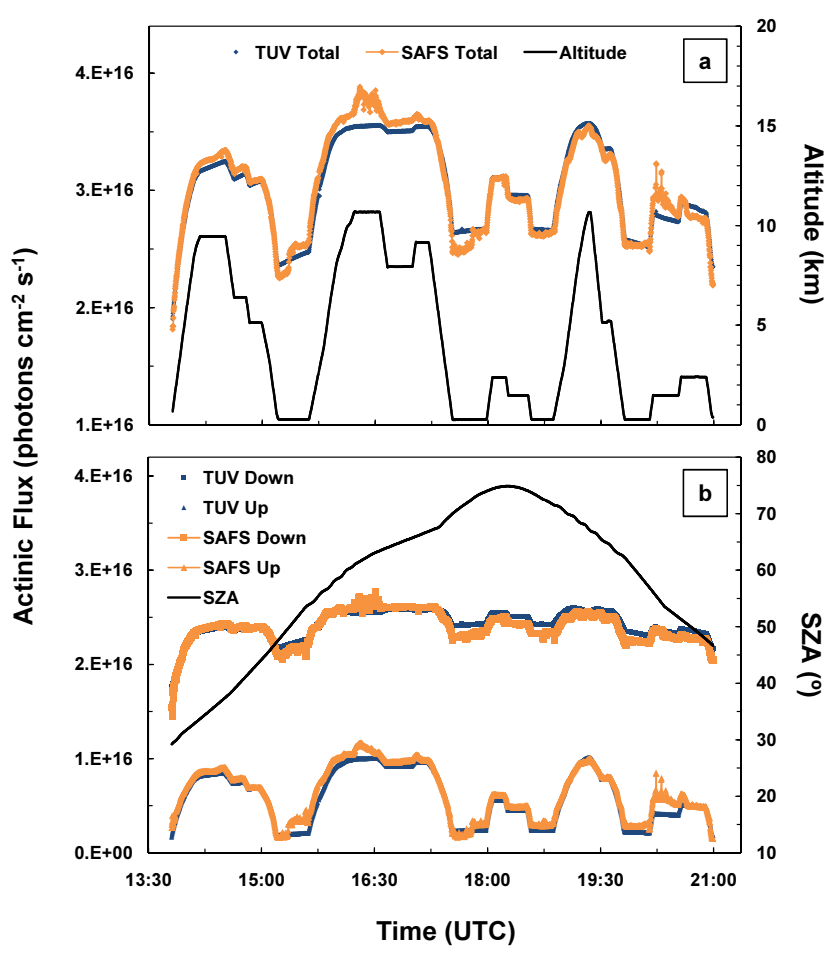

Fig. 1. Time series of measured (clear-sky) and cloud-free modeled (a) total and (b) down-welling and up-welling actinic flux for 13 August. Aircraft altitude and SZA variations are also shown in panels (a) and (b), respectively.

\subsection{Dependence on altitude and solar zenith angle}

The variations of $Q^{\downarrow}$ and $Q^{\uparrow}$ with altitude are shown in Fig. 4. Considering both cloudy and clear data, above $\sim 2 \mathrm{~km}$ values are variable but consistently larger than unity, with medians reaching 1.1 for $Q^{\downarrow}$ and 1.3 for $Q^{\uparrow}$. The cloud-free bias is also positive above $2 \mathrm{~km}$, though with reduced values that approach the experimental and modeling uncertainties. At the lowest altitudes, values of both $Q^{\downarrow}$ and $Q^{\uparrow}$ fall below unity, which is easily understood if clouds are present overhead. In the absence of clouds, the low altitude reductions

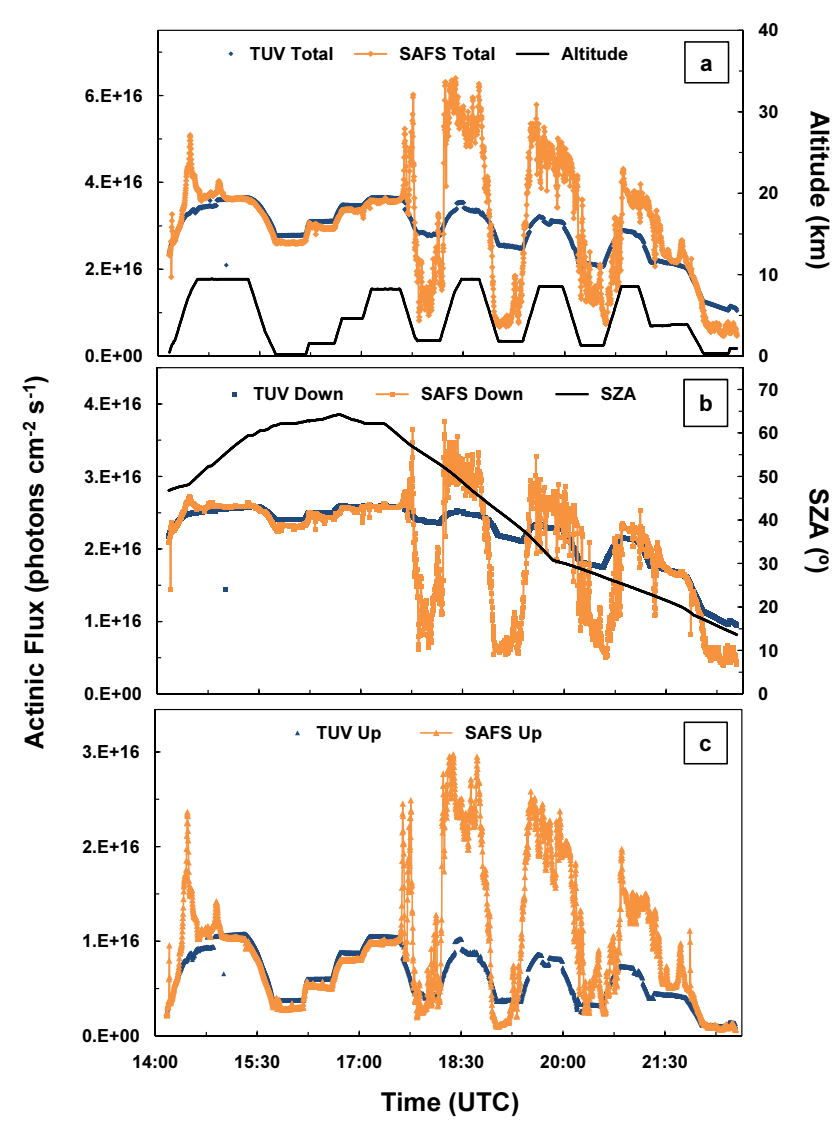

Fig. 2. Time series of measured (cloudy) and cloud-free modeled (a) total, (b) down-welling, and (c) up-welling actinic flux for $7 \mathrm{Au}$ gust. Aircraft altitude and SZA variations are also shown in panels (a) and (b), respectively.

and variability are more difficult to explain, and probably arise from a combination of aerosol effects, surface albedo variations, and imperfect separation of cloud-free situations from the whole data set.

The rather weak variations of $Q^{\downarrow}$ and $Q^{\uparrow}$ with solar zenith angle are shown in Fig. 5. For $Q^{\downarrow}$ the variations are well within the accuracy of the observations, with no obvious 


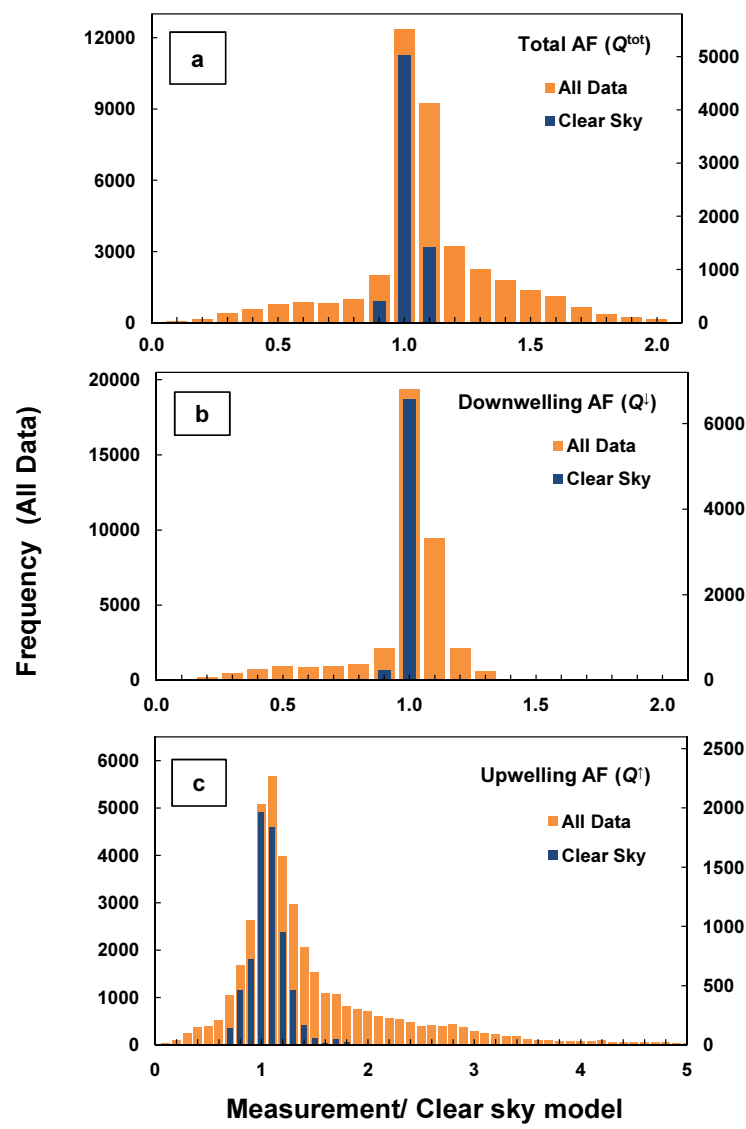

Fig. 3. Frequency distribution of the measurement/model ratios for (a) total, (b) down-welling, and (c) up-welling actinic flux. Blue bars are for cloud-free skies, orange bars for all sky conditions.

dependence on solar zenith angle. A slight decrease with increasing angle is noted for $Q^{\uparrow}$ in cloud-free conditions, with best agreement around $50^{\circ}-70^{\circ}$ and a $10-15 \%$ overestimation at low sun. The precise origin of this variation is not known but may be related to surface reflections that deviate from Lambertian behavior.

\subsection{Correlation between up-welling and down-welling radiation}

Based on the discussion so far it is apparent that clouds can cause a great variety of perturbations to the actinic flux, depending on their morphology, optical properties, and location relative to the observation point. Nevertheless, it seems reasonable to presume that the perturbations to the up-welling and down-welling radiation fields are not entirely independent, and this is indeed the case. The correlation between the observed perturbations in up-welling and down-welling radiation (measurement divided by cloud-free model, i.e. $Q^{\uparrow}$ vs. $Q^{\downarrow}$ ) is shown in Fig. 6, with the color scale indicating the frequency of occurrence of the perturbed values. The correlation shows two quasi-linear regimes, between the origin

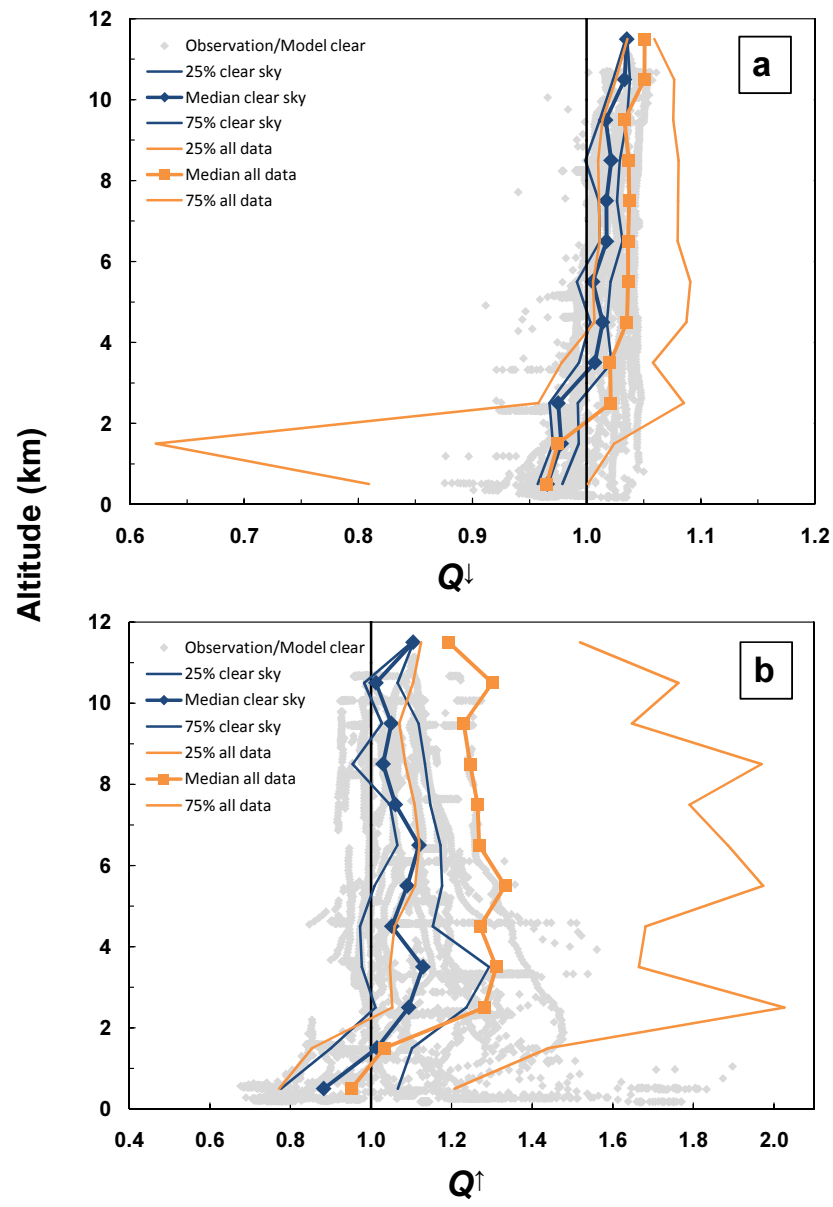

Fig. 4. Altitude variation of the ratio of observed to cloud-free model actinic fluxes, for cloud-free (blue) and all (orange) conditions. Panel (a) is for down-welling radiation, panel (b) for upwelling. Central line (with markers) gives median values while thinner lines show the quartiles. Grey points show individual data points for cloud-free conditions.

to the unity point $(1 ; 1)$, and from there sharply upward, suggesting that some simple principles apply in this otherwise extremely complex problem.

Sensitivity studies with the TUV model were used to explore whether the correlations seen in Fig. 6 could be explained. Horizontally uniform clouds were added to the model, with wide value ranges of optical depth, geometric thickness, and altitude. Broken clouds covering a specific fraction of the area were also considered, by computing both the clear and overcast cases and averaging the diffuse radiation in proportion to the cloud cover (Nack and Green, 1974; Lantz et al., 1996; Crawford et al., 2003), with separate consideration of whether the direct sun is observable or obscured by cloud. Calculations were repeated over a range of solar zenith angles. For direct comparison with Fig. 6, we computed the ratio of the cloudy-case TUV calculation to the cloud-free TUV calculation, for both up-welling 

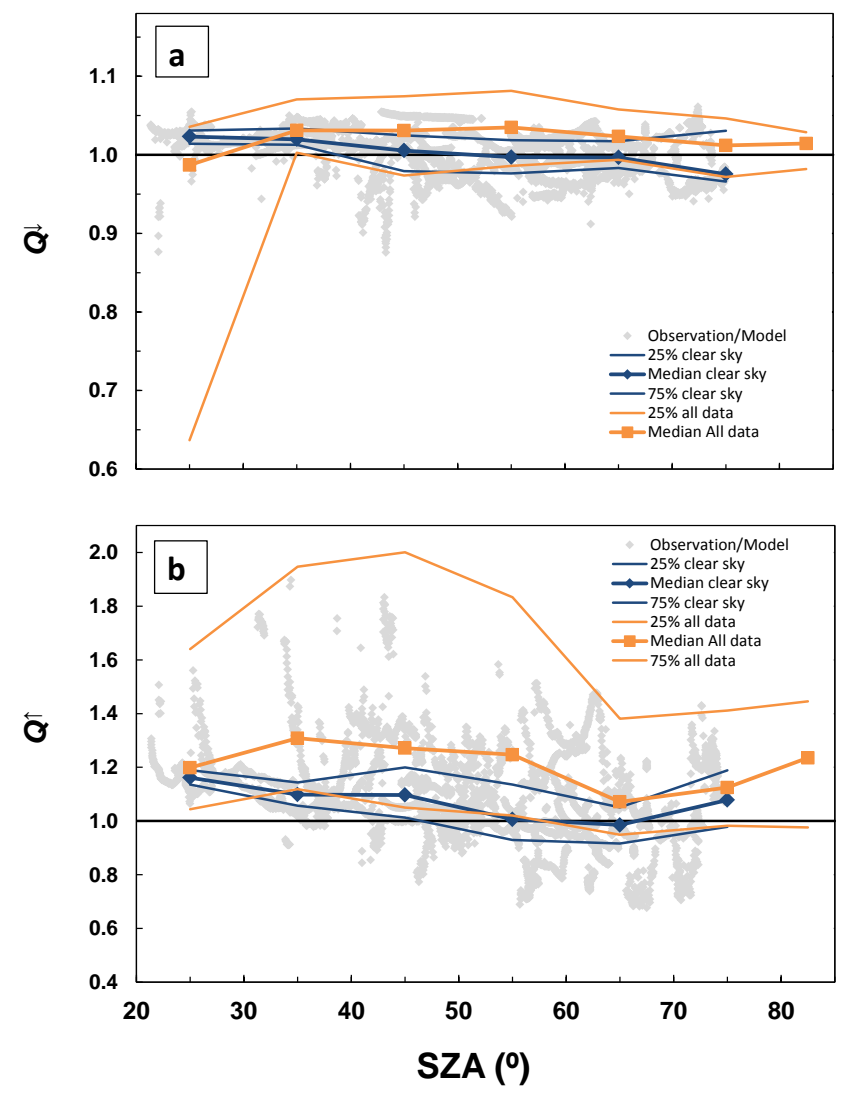

Fig. 5. Solar zenith angle variation of the ratio of observed to cloudfree model actinic fluxes, for cloud-free (blue) and all (orange) conditions. Panel (a) is for down-welling radiation, panel (b) for upwelling. Central line (with markers) gives median values while thinner lines show the quartiles. Grey points show individual data points for cloud-free conditions.

and down-welling radiation. The TUV results are shown in Fig. 7, where they are superimposed onto the ratios of observations to clear sky model values from Fig. 6. It is evident that the model predicts ratios and slopes comparable to those observed, even recognizing that the observations sample the actual flight environments while the model sensitivities span arbitrarily selected ranges of conditions. Above clouds, values of $Q^{\downarrow}$ and $Q^{\uparrow}$ are always larger than unity, while below clouds they are usually reduced except for very thin clouds for which $Q^{\downarrow}$ can be slightly larger than 1 . Inside clouds, both reductions and enhancements in $Q^{\downarrow}$ and $Q^{\uparrow}$ are possible.

\section{Discussion}

\subsection{Representative cases}

To facilitate interpretation, Table 2 lists the sky conditions that could be present above and below the aircraft, with their likely effect on up-welling and down-welling radiation and

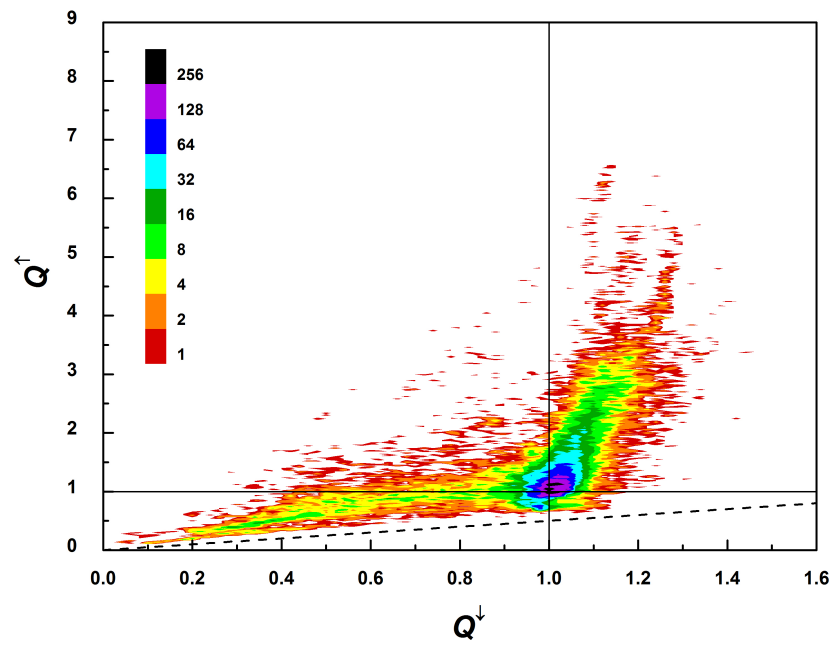

Fig. 6. Correlation of observed to model (clear sky) actinic flux ratios for up-welling and down-welling radiation observed during INTEX-NA (all flights). Color scale gives frequency of occurrence of values. Dashed line give approximate the lower bound of observed values.

their corresponding regimes marked in Fig. 7. Perhaps the most critical consideration is whether the direct sun is observed at the aircraft (cases 1-4), since the upward-facing SAFS gathers both direct and diffuse light without distinction. For cloud-free conditions (case 1) both $Q^{\uparrow}$ and $Q^{\downarrow}$ equal unity. If clouds are present below the aircraft (case 2), $Q^{\uparrow}$ is enhanced significantly by direct reflection and $Q^{\downarrow}$ is enhanced slightly by Rayleigh scattering of the cloudreflected radiation. Broken clouds above the aircraft are usually brighter than the sky radiance, leading to enhancement in $Q^{\downarrow}$, while $Q^{\uparrow}$ will be enhanced or reduced depending on whether below the aircraft clouds are present (case 4) or not (case 3). If the sun is blocked (cases 5-8) $Q^{\downarrow}$ is always reduced, especially if this blocking is achieved by only a few scattered clouds overhead (e.g. in cases 5 and 6). The response of $Q^{\uparrow}$ depends, as before, on whether clouds are present or not below the aircraft. With clouds only above the airplane but not below (case 7) both $Q^{\downarrow}$ and $Q^{\uparrow}$ are reduced. Case 8, with clouds below and above the aircraft, can be interpreted as being within the cloud, or equivalently between cloud layers, with values of $Q^{\downarrow}$ and $Q^{\uparrow}$ sensitive to the vertical position within clouds and solar zenith angle; the values given in Table 2, $Q^{\downarrow}<1$ and $Q^{\uparrow}>1$, are approximately representative for high sun and the middle of the cloud. These effects can occasionally be different than shown (e.g., here clouds are assumed to be brighter than clear sky, although very heavy clouds could be darker), and are intended subjectively as typical rather than all-encompassing. 


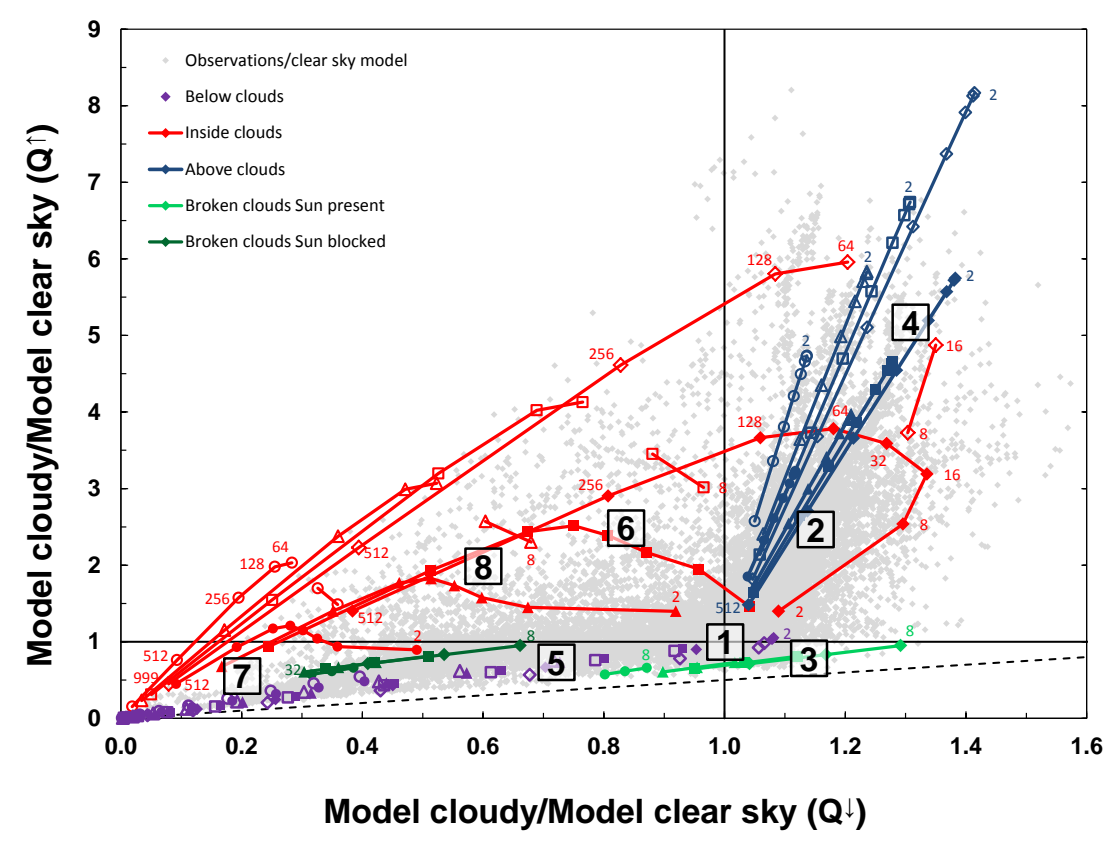

Fig. 7. Correlation of cloudy-model to clear-sky-model actinic flux ratios for up-welling and down-welling radiation, for selected ranges of cloud conditions as indicated in the legend. Grey points are observations/clear-sky model ratios from Fig. 6. Large numbers refer to cases from Table 2. Small numbers give cloud optical depths (range 2-999), for cloud between 3 and $4 \mathrm{~km}$. Closed and open markers denote different surface elevations (sea level and $2 \mathrm{~km}$, respectively). Airplane altitude is $2.5,3.5$, and $4.5 \mathrm{~km}$ for below, inside, and above cloud, respectively. Calculations at solar zenith angles of 0, 45, 60, and 80 degrees are given by diamonds, squares, triangles, and circles, respectively.

\section{Conclusions}

Actinic flux measurements taken onboard the NASA DC-8 aircraft during the 2004 INTEX-NA campaign were shown to agree with the TUV model for cloud-free conditions over a large range of aircraft altitudes, surface elevations, and solar zenith angles, with a campaign-averaged measurement to model ratio of $1.01 \pm 0.04$. Similar agreement for cloudfree conditions was obtained by Lefer et al. (2003). When clouds were present, measurements showed both positive and negative deviations from the cloud-free model values, and detailed examination of up-welling and down-welling components revealed a correlation in two quasi-linear regimes, which are indicated mainly by whether the sun is illuminating the aircraft or not. The exact cloud properties (optical depth, altitude, area coverage) were not known at any time during the flight, but TUV model simulations using a reasonable range of cloud properties generated similar correlations.

The effect of clouds on the vertical profile of the actinic flux is much more complex than the effect on the values at the surface. Lantz et al. (1996) and Crawford et al. (2003) showed that surface actinic fluxes are on average reduced by clouds, but partial cloud cover can cause temporary enhancements when the sun is showing, leading to characteristic bimodal distributions of the deviation from cloud-free skies (see Fig. 12 of Lantz et al., 1996, and Fig. 3 of Craw- ford et al., 2003). Actinic fluxes aloft can be systematically enhanced or reduced by clouds, depending on the height of interest (e.g. the aircraft) relative to the height of the clouds. Furthermore, clouds can be present simultaneously above and below the point of interest. Thus, rather than the simple bimodal distribution found in surface studies, the frequency of deviations is more generally represented by the two-part correlation between up-welling and down-welling fluxes, as shown in Figs. 6 and 7.

These issues have important implications for evaluating cloud-photolysis interactions in regional and global chemistry-transport models. The accuracy of modeled photolysis rates depends not only on radiative transfer parameterizations, but on the models' ability to predict horizontal and vertical cloud distributions and their optical properties. To our knowledge, no such evaluation has yet been made, even though aircraft-based actinic flux data are increasingly available. Our analysis of the INTEX-NA data shows some of the difficulties but also some opportunities in carrying out such evaluations. Direct comparisons of measured and modeled actinic fluxes at specific points and times (e.g. time-series along a flight path) are unlikely to be successful if clouds are present, because of high sensitivity to cloud details that may not be fully represented in the model. On the other hand, evaluations of statistical properties such as means, standard deviations, skewness, and variations with altitude and solar 
zenith angle may be more reasonable objectives, and simultaneous measurements of up-welling and down-welling radiation can provide additional tests. Ideally, a chemistrytransport model simulation of a flight should yield plots such as Figs. 3-7 that closely resemble the observations. Additional constraints could come from detailed spectral comparisons to distinguish the effects of Rayleigh scattering from those of clouds and possibly aerosols, and of gaseous absorbers such as $\mathrm{O}_{3}$ and $\mathrm{NO}_{2}$. A successful evaluation of photolysis processes in the presence of clouds would substantially increase the confidence in the predictive ability of chemistry-transport models.

\section{Appendix A}

\section{Simple analytic model}

A simple analytical estimation for the effect of clouds on the actinic flux at different altitudes can be obtained based on several idealizations: (i) Whenever the collimated direct solar beam is converted into diffuse light, be this by cloud or surface reflection, the actinic flux is modified as discussed by Madronich (1987). (ii) Partial cloud cover above the aircraft is treated by superposition of the cloud-free and overcast cases, as discussed by Nack and Green (1974). (iii) Clouds below the aircraft are treated as an effective enhancement of the surface albedo. (iv) Rayleigh scattering is ignored, except that it can be considered equivalent to optically thin clouds above and below the aircraft.

Figure A1a shows the idealized clear sky situation. The direct solar beam actinic flux, $F^{o}$, is incident at angle $\theta$ onto the aircraft and onto the Earth's surface where it is partially reflected. The surface is assumed to be Lambertian with albedo $A_{o}$, so the reflected light is isotropic and the upwelling actinic flux is $2 \mu A_{o} F^{o}$, where $\mu=\cos \theta$, in accordance with the collimated-to-isotropic conversion discussed by Madronich (1987):

$F_{o}^{\uparrow}=2 \mu A_{o} F^{o}$

The down-welling diffuse radiation is neglected in the cloud-free situation (since Rayleigh scattering is ignored).

The extension of this simple model to a cloudy atmosphere is shown in Fig. A1b. Clouds above the aircraft occupy a fraction $c$ of the area, so that $c=0$ is cloud-free while $c=1$ is overcast. Where present, the clouds transmit a fraction $T$ of the direct irradiance, and with the assumption that the transmitted light becomes mostly isotropic, the transmitted actinic flux is $2 \mu T F^{o}$. The clouds also reflect a fraction $R$ of the up-welling diffuse radiation $F^{\uparrow}$. Summing these two contributions, the down-welling diffuse flux $F^{\downarrow}$ at the aircraft is given by:

$F^{\downarrow}=c\left[2 \mu T F^{o}+R F^{\uparrow}\right]$
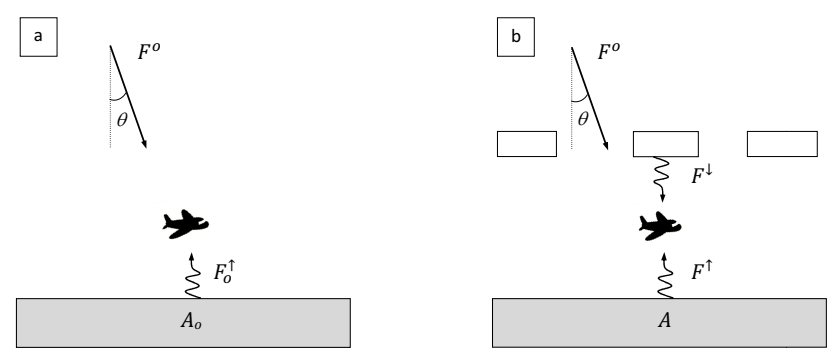

Fig. A1. (a) Cloud free situation showing the aircraft illuminated by the direct solar beam $F^{o}$ incident with solar zenith angle $\theta$, and the up-welling radiation $F_{o}^{\uparrow}$ reflected by the Lambertian surface of albedo $A_{o}$. Rayleigh scattering is neglected in this idealized example. (b) Addition of clouds above the aircraft results in a downwelling diffuse actinic flux $F^{\downarrow}$, while clouds below the aircraft increase the reflectivity below the aircraft with an effective albedo $A$ to give an up-welling actinic flux $F^{\uparrow}$.

Rayleigh-scattered radiation is again ignored. Below the aircraft, we consider the possibility of reflections not only from the surface (as was the case in Fig. A1a), but also from low-lying clouds. These low clouds contribute to an overall albedo $A$, as seen from the aircraft, that will generally be larger than $A_{o}$ and may even approach unity if heavy cloud cover is present below. With this extended interpretation of the albedo, the up-welling radiation is given by:

$$
F^{\uparrow}=A\left[(1-c) 2 \mu F^{o}+F^{\downarrow}\right]
$$

Note in this equation that the direct solar beam is incident on only a fraction $1-c$ of the surface, while the diffuse down-welling is incident on the entire surface because its dependence on partial cloud cover was already included in Eq. (A2). Equations (A2) and (A3) can be solved simultaneously,

$$
\begin{aligned}
F^{\downarrow} & =\frac{2 \mu F^{o}[(1-c) c R A+c T]}{1-c R A} \\
F^{\uparrow} & =\frac{2 \mu A F^{o}[(1-c)+c T]}{1-c R A}
\end{aligned}
$$

showing that the diffuse radiation fields from the upper and lower hemisphere are closely related. Their ratio,

$$
\frac{F^{\uparrow}}{F^{\downarrow}}=A \frac{(1-c)+c T}{(1-c) c R A+c T}
$$

is independent of solar zenith angle but determined by the values of $c, R, T$, and $A$. Some additional simplification can be obtained by assuming $T+R \sim 1$, but it should be noted that $T$ refers to transmission of the direct beam while $R$ refers to reflection of diffuse radiation, so that their sum may in general not be exactly unity. The limits are easily evaluated, e.g. with the approximation $T+R \sim 1$ :

for $c \rightarrow 1, \quad F^{\uparrow} \rightarrow A F^{\downarrow} ; \quad$ for $c \rightarrow 0, \quad F^{\downarrow} \rightarrow 0 ; \quad$ for $T \rightarrow 1$, $c F^{\uparrow} \rightarrow A F^{\downarrow}$; for $T \rightarrow 0, F^{\downarrow} \rightarrow c F^{\uparrow}$. 
Note that this formulation has some similarities to the independent pixel approximation, IPA (e.g. Nack and Green, 1974), but it differs by allowing the direct solar beam to be a source for multiply reflected radiation between the lower surface and the upper cloud cover, while in the IPA it would be reflected only once, at the lower surface.

It is interesting to compare the actinic fluxes in cloudy conditions to those that would have been estimated for clear conditions, as was done with the observations in Fig. 6. Recalling that for the cloud free case the down-welling flux is simply the direct solar beam, $F^{o}$, and the up-welling flux,

$F_{o}^{\uparrow}$, is given by Eq. (A1), the cloudy/clear ratios, $Q^{\downarrow}$ and $Q^{\uparrow}$, are:

$Q^{\uparrow}=\frac{F^{\uparrow}}{F_{o}^{\uparrow}}=\frac{A}{A_{o}} \frac{[(1-c)+c T]}{1-c R A}$

$Q^{\downarrow}=\frac{F^{\downarrow}+\delta F^{o}}{F^{o}}=\frac{2 \mu[(1-c) c R A+c T]}{1-c R A}+\delta$

where $\delta=1$ if the sun is present, and $\delta=0$ if the sun is obscured. Figures 6 and 7 are essentially correlations of $Q^{\downarrow}$ vs. $Q^{\uparrow}$. In reference to Table 2, cases 1 and 2 in which no clouds are present above the aircraft $(c=0, \delta=1)$ simply limit to the values

$Q^{\uparrow}=\frac{A}{A_{o}}$

$Q^{\downarrow}=1$

with $Q^{\uparrow}=1$ for case 1 in which the lower hemisphere is also cloud-free $\left(A=A_{o}\right)$. These cases are also shown in Fig. 7, however with $Q^{\downarrow}$ somewhat larger than unity due to multiple interactions between clouds below the aircraft and Rayleigh scattering above (the latter not being included in the simple model). Cases 7 and 8 occur when conditions above the aircraft are overcast $(c=1, \delta=0)$. In this case

$$
\begin{aligned}
Q^{\uparrow} & =\frac{A}{A_{o}} \frac{T}{1-R A} \\
Q^{\downarrow} & =\frac{2 \mu T}{1-R A}
\end{aligned}
$$

showing that both $Q^{\downarrow}$ and $Q^{\uparrow}$ scale with cloud transmission $T$ and enhancements from multiple albedo-cloud reflections, $\sum_{i=0}^{\infty}(R A)^{i}=(1-R A)^{-1}$. With no clouds below the aircraft $\left(A=A_{o}\right.$, case 7) the enhancement can be quite modest, making both $Q^{\downarrow}$ and $Q^{\uparrow}$ small, as shown in Fig. 7. In case 8 (within cloud), values of $A / A_{o}$ and therefore $Q^{\uparrow}$ are expected to be large, as also seen in Fig. 7. With broken clouds (cases 3-6, $0<c<1$ ), the expressions are more complex and depend on detailed cloud properties.

The slopes of these correlations can also be evaluated, e.g., if the sun is not showing $(\delta=0)$,

$$
\frac{Q^{\uparrow}}{Q^{\downarrow}}=\left[\frac{A}{A_{o}}\right]\left[\frac{1}{2 \mu}\right]\left[\frac{(1-c)+c T}{(1-c) c R A+c T}\right]
$$

$$
\begin{gathered}
\text { If } c=1 \text { (overcast), } \\
\frac{Q^{\uparrow}}{Q^{\downarrow}}=\left[\frac{A}{A_{o}}\right]\left[\frac{1}{2 \mu}\right]
\end{gathered}
$$

and since $A \geq A_{o}$ and $\mu \leq 1$, the smallest possible value of $Q^{\uparrow} / Q^{\downarrow}$ is 0.5 , in agreement with both observations (the lower dashed line of Fig. 6) and most model calculations (Fig. 7). More generally, since $c \leq 1$, the third factor on the right hand side of Eq. (A13) is always $\geq 1$ (because in its denominator $c R A \leq 1)$. Therefore $Q^{\uparrow} / Q^{\downarrow} \geq 0.5$ whenever the sun is not showing. When the sun is showing $(\delta=1)$, the value of $Q^{\downarrow}$ is essentially shifted by 1 ,

$\frac{Q^{\uparrow}}{Q^{\downarrow}-1}=\left[\frac{A}{A_{o}}\right]\left[\frac{1}{2 \mu}\right]\left[\frac{(1-c)+c T}{(1-c) c R A+c T}\right]$

i.e., the relationship is similar to the $\delta=0$ case after accounting for the direct beam offset.

\section{A1 Comparison with the Chang et al. (1987) parameterization}

For the total actinic flux, $Q^{\text {tot }}$ is defined as the ratio of the total actinic flux in cloudy relative to cloud-free conditions, including all directional components:

$Q^{\mathrm{tot}}=\frac{\delta F^{o}+F^{\downarrow}+F^{\uparrow}}{F^{o}+F_{o}^{\uparrow}}$

This analytical formulation can be compared with the parameterization proposed by Chang et al. (1987), in which cloudy-sky photolysis coefficients are obtained by multiplying cloud-free values with a correction factor that was estimated from fitting radiative transfer model results. In the notation of the present study, their correction factor $Q^{\text {tot }}$ is given by

$Q^{\text {tot }}=1+\alpha_{i}(1-t) \mu$ above cloud layer

$Q^{\text {tot }}=1.4 \mu$ in cloud layer

$Q^{\text {tot }}=1.6 t \mu$ below cloud layer

where $t$ is the transmission of the cloud layer, and the coefficient $\alpha_{i}$ ranges between 0.7 and 1.3 depending on the molecule of interest. Considering first the above-cloud case, we note that in our formulation $c=0$ since it refers only to overhead clouds. Then, from Eqs. (A1), (A4) and (A5), $Q^{\text {tot }}$ reduces to:

$Q^{\text {tot }}=\frac{1+2 \mu A}{1+2 \mu A_{o}}$

Since $2 \mu A_{o}$ is usually much smaller than unity, this can be approximated as:

$Q^{\mathrm{tot}}=1+2 \mu A\left(1-2 \mu A_{o}-\frac{A_{o}}{A}\right)$ 
which has the form of the Chang et al. (1987) expression (Eq. A17), with the identification $A \sim 1-t$, and the value of $\alpha_{i}$ predicted to be somewhat smaller than 2, although larger than the range of values given by Chang et al. This is because of the assumption that only direct sunlight is incident on the cloud tops, while in reality Rayleigh-scattered contributions are significant, particularly at the shorter wavelengths.

Considering next the in-cloud and below-cloud situations, we evaluate $Q^{\text {tot }}$ for $\delta=0$ and $c=1$ (overcast), so that

$$
Q^{\mathrm{tot}}=\frac{2 \mu T(1+A T)}{(1-R A)(1+2 \mu A)}
$$

Below cloud $A=A_{o}$ and is typically small, so that keeping only the terms that are first order in $A_{o}$ gives:

$$
Q^{\text {tot }}=2 \mu T\left[1+A_{o}(T+R-2 \mu)\right] \sim 2 \mu T\left[1-A_{o}(2 \mu-1)\right]
$$

where in the last approximation $T+R \sim 1$ was used. This corresponds well to the below-cloud expression of Chang et al. (1987), with the constant 1.6 replaced by the factor $2\left[1-A_{o}(2 \mu-1)\right]$ that depends weakly on surface albedo and solar zenith angle.

For the in-cloud situation, the effective albedo $A$ is much larger than the surface albedo $A_{o}$, and Eq. (A22) cannot be approximated as above. However a simple limit is found if $A$ approaches unity (heavy cloud below), with the further approximation $1-R \sim T$ :

$$
Q^{\mathrm{tot}}=\frac{2 \mu(1+T)}{1+2 \mu}
$$

Comparison with the Chang et al. parameterization shows that the constant multiplier 1.4 is actually expected to be $2(1+T) /(1+2 \mu)$ and so is somewhat dependent on both $T$ and $\mu$. For small values of $T$ (deep within the cloud) the value ranges from $2 / 3$ to 2 , while near cloud top ( $T$ near unity) the range is from $4 / 3$ to 4 . The constant given by Chang et al. (1987) represents a vertically and temporally averaged value, while the analytic formulation allows, through the selection of values for $A$ and $T$, evaluation at different altitudes within the cloud.

In summary, the analytical formulation given here is consistent with the simple cloud correction factors given by Chang et al., showing their theoretical origin, and providing refined dependencies on cloud transmission and solar zenith angle for coefficients that are held constant in the original parameterization.

Acknowledgements. G. G. Palancar and B. M. Toselli would like to thank to CONICET, SeCyT (UNC), and the Agencia Nacional de Promoción Científica y Tecnológica (ANCyT - FONCyT). The National Center for Atmospheric Research is sponsored by the National Science Foundation.

Edited by: A. Hofzumahaus

\section{References}

Bais, A., Madronich, S., Crawford, J., Hall, S. R., Mayer, B., VanWeele, M., Lenoble, J., Calvert, J. G., Cantrell, C. A., Shetter, R. E., Hofzumahaus, A., Koepke, P., Monks, P. S., Frost, G., McKenzie, R., Krotkov, N., Kylling, A., Lloyd, S., Swartz, W. H., Pfister, G., Martin, T. J., Roeth, E. -P., Griffioen, E., Ruggaber, A., Krol, M., Kraus, A., Edwards, G. D., Mueller, M., Lefer, B. L., Johnston, P., Schwander, H., Flittner, D., Gardiner, B. G., Barrick, J., and Schmitt, R.: International Photolysis Frequency Measurement and Model Intercomparison: Spectral Actinic Solar Flux Measurements and Modeling, J. Geophys. Res., 108, 8543, doi:1029/2002/JD002891, 2003.

Brasseur, A.-L., Ramaroson, R., Delannoy, A., Skamarock. W., and Barth, M.: Three-Dimensional Calculation of Photolysis Frequencies in the Presence of Clouds and Impact on Photochemistry, J. Atmos. Chem., 41, 211-237, 2002.

Chang, J. S., Brost, R. A., Isaksen, I. S. A., Madronich, S., Middleton, P., Stockwell, W. R., and Walcek, C. J.: A ThreeDimensional Eulerian Acid Deposition Model: Physical Concepts and Formulation, J. Geophys. Res., 92(D12), 1468114700, 1987.

Crawford, J., Davis, D., Chen, G., Shetter, R., Müller, M., Barrick, J., and Olson, J.: An assessment of cloud effects on photolysis rate coefficients: Comparison of experimental and theoretical values, J. Geophys. Res., 104(D5), 5725-5734, 1999.

Crawford, J., Shetter, R., Lefer, B., Cantrell, C., Junkermann, W., Madronich, S., and Calvert, J.: Cloud impacts on UV spectral actinic flux observed during the International Photolysis Frequency Measurement and Model Intercomparison (IPMMI), J. Geophys. Res. 108(D16), 8545, doi:10.1029/2002JD002731, 2003.

De Roode, S. R., Duynkerke, P. G., Boot, W., and Van der Hage, J. C. H.: Surface and tethered-balloon observations of actinic flux: Effects of arctic stratus, surface albedo, and solar zenith angle, J. Geophys. Res., 106, 27497-27507, 2001.

GTOPO30 data base, US Geological Survey's EROS Data Center: http://eros.usgs.gov/products/elevation/gtopo30/gtopo30.html, last access: 27 December 2007.

Jacob, D. J., Gottlieb, E. W., and Prather, M. J.: Chemistry of a polluted cloudy boundary layer, J. Geophys. Res., 94, 1297513002, 1989.

Jäkel, E., Wendisch, M., Kniffka, A., and Trautmann, T.: Airborne system for fast measurements of upwelling and downwelling spectral actinic flux densities, Appl. Opt., 44, 434-444, 2005.

Jet Propulsion Laboratory: DEM auxiliary datasets preparation plan: digital elevation mapping support to the EOS/AM1 platform. JPL D13508, Release 2, JPL, California Institute of Technology, Pasadena, California, USA, 65 pp., 1997.

Junkermann, W.: Measurements of the $\mathrm{J}\left(\mathrm{O}^{1} \mathrm{D}\right)$ actinic flux within and above stratiform clouds and above snow surfaces, Geophys. Res. Lett., 21, 793-797, 1994.

Kelley, P., Dickerson, R. R., Luke, W. T., and Kok, G. L.: Rate of $\mathrm{NO}_{2}$ photolysis from the surface to $7.6 \mathrm{~km}$ altitude in clear-sky and clouds, Geophys. Res. Lett. 22, 2621-2624, 1995.

Kylling, A., Webb, A. R., Kift, R., Gobbi, G. P., Ammannato, L, Barnaba, F., Bais, A., Kazadzis, S., Wendisch, M., Jäkel, E., Schmidt, S., Kniffka, A., Thiel, S., Junkermann, W., Blumthaler, M., Silbernagl, R., Schallhart, B., Schmitt, R., Kjeldstad, B., Thorseth, T. M., Scheirer, R., and Mayer, B.: Spectral actinic flux in the lower troposphere: measurement and 1-D simulations for 
cloudless, broken cloud and overcast situations, Atmos. Chem. Phys. 5, 1975-1997, doi:10.5194/acp-5-1975-2005, 2005.

Landgraf, J. and Crutzen, P. J.: An efficient method for online calculations of photolysis and heating rates, J. Atmos. Sci., 55, 863878, 1998.

Lantz, K. O., Shetter, R. E., Cantrell, C. A., Flocke, S. J., Calvert, J. G., and Madronich, S.: Theoretical, actinometric, and radiometric determinations of the photolysis rate coefficient of $\mathrm{NO}_{2}$ during the Mauna Loa Observatory Photochemistry Experiment 2, J. Geophys. Res., 101, 14613-14629, 1996.

Lefer, B., Shetter, R., Hall, S., Crawford, J., and Olson, J.: Impact of clouds and aerosols on photolysis frequencies and photochemistry during TRACE-P: 1 . Analysis using radiative transfer and photochemical box models, J. Geophys. Res., 108(D21), 8821, doi:10.1029/2002JD003171, 2003.

Lelieveld, J. and Crutzen, P. J.: Influences of cloud photochemical processes on tropospheric ozone, Nature, 343, 6255, 227-233, 1990.

Liu, H., Crawford, J. H., Pierce, R. B., Norris, P., Platnick, S., Chen, G., Logan, J. A., Yantosca, R. M., Evans, M. J., Kittaka, C., Feng, Y., and Tie, X.: Radiative effect of clouds on tropospheric chemistry in a global three-dimensional chemical transport model,J. Geophys. Res., 111, D20303, doi:10.1029/2005JD006403, 2006.

Los, A., van Weele, M., and Duynkerke, P. G.: Actinic fluxes in broken cloud fields, J. Geophys. Res. 102, 4257-4266, 1997.

Madronich, S.: Photodissociation in the atmosphere 1. Actinic flux and the effect of ground reflections and clouds, J. Geophys. Res., 92, 9740-9752, 1987.

Madronich, S.: UV radiation in the natural and perturbed atmosphere, in: UV-B radiation and ozone depletion: effects on humans, animals, plants, microorganisms, and materials, edited by: Tevini, M., Lewis Publishers, Boca Raton, FL, USA, 17-61, 1993.

Madronich, S., Hastie, D. R., Schiff, H. I., and Ridley, B., A.: Measurements of the photodissociation coefficient of $\mathrm{NO}_{2}$ in the atmosphere, II. Stratospheric measurements, J. Atmos. Chem., 3, 233-245, 1985.

Mayer, B. and Kylling, A.: Technical note: The libRadtran software package for radiative transfer calculations - description and examples of use, Atmos. Chem. Phys., 5, 1855-1877, doi:10.5194/acp-5-1855-2005, 2005.

Meier, R. R., Anderson, G. P., Cantrell, C. A., Hall, L. A., Lean, J., Minschwaner, K. M., Shetter, R. E., Shettle, E. P., and Stamnes, K., Review paper: Actinic radiation in the terrestrial atmosphere, J. Atmos. Sol.-Terr. Phys., 59, 2111-2157, 1997.

Nack, M. and Green, A.: Influence of clouds, haze, and smog on the middle ultraviolet reaching the ground, Appl. Opt., 13(10), 2405-2415, 1974.

USSA, US Standard Atmosphere, National Oceanic and Atmospheric Administration (NOAA), National Aeronautics and Space Administration (NASA), United States Air Force (USAF), US Government Printing Office, Washington, DC, USA, 241 pp., 1976.

Neckel, H. and Labs, D.: The solar radiation between 3300 and $12500 \AA$ Å, Sol. Phys., 90, 205-258, 1984.

Petropavlovskikh, I.: Evaluation of Photodissociation Coefficient Calculations for Use in Atmospheric Chemical Models, Ph.D. thesis, University of Brussels/ National Center for Atmospheric Research, Cooperative Thesis No. 159, NCAR, Boulder, Col- orado, USA, 1995.

Pfister, G., Baumgartner, D., Maderbacher, R., and Putz, E.: Aircraft measurements of photolysis rate coefficients for ozone and nitrogen dioxide under cloudy conditions, Atmos. Environ. 34, 4019-4029, 2000.

Pour-Biazar, A., McNider, R. T., Roselle, S. J., Suggs, R., Jedlovec, G., Byun, D. W., Kim, S., Lin, C. J., Ho, T. C., Haines, S., Dornblaser, B., and Cameron, R.: Correcting photolysis rates on the basis of satellite observed clouds, J. Geophys. Res. 112 D10302, doi:10.1029/2006JD007422, 2007.

Shetter, R. E. and Müller, M.: Photolysis frequency measurements using actinic flux spectroradiometry during the PEM-Tropic mission: Instrumentation description and some results, J. Geophys. Res., 104(D5), 5647-5661, 1999.

Shetter, R. E., Cinquini, L., Lefer, B. L., Hall, S. R., and Madronich, S.: Comparison of airborne measured and calculated spectral actinic flux and derived photolysis frequencies during the PEM Tropics B mission, J. Geophys. Res. 108(D2), 8234, doi:10.1029/2001JD001320, 2003.

Singh, H., Brune, W., Crawford, J., Jacob, D., and Russell, P.: Overview of the summer 2004 Intercontinental Chemical Transport Experiment-North America (INTEX-A), J. Geophys. Res., 111, D24S01, doi:10.1029/2006JD007905, 2006.

Stamnes, K., Tsay, S., Wiscombe, W., Jayaweera, K.: Numerically stable algorithm for discrete-ordinate-method radiative transfer in multiple scattering and emitting layered media, Appl. Opt., 27, 2502-2509, 1988.

Thiel, S., Ammannato, L., Bais, A., Bandy, B., Blumthaler, M., Bohn, B., Engelsen, O., Gobbi, G. P., Gröbner, J., Jäkel, E., Junkermann, W., Kazadzis, S., Kift, R., Kjeldstad, B., Kouremeti, N., Kylling, A., Mayer, B., Monks, P. S., Reeves, C. E., Schallhart, B., Scheirer, R., Schmidt, S., Schmitt, R., Schreder, J., Silbernagl, R., Topaloglou, C., Thorseth, T. M., Webb, A. R., Wendisch, M., and Werle, P., Influence of clouds on the spectral actinic flux density in the lower troposphere (INSPECTRO): overview of the field campaigns, Atmos. Chem. Phys., 8, 1789-1812, doi:10.5194/acp-8-1789-2008, 2008.

Tie, X., Madronich, S., Walters, S., Zhang, R., Rasch, P., and Collins, W.: Effect of clouds on photolysis and oxidants in the troposphere, J. Geophys. Res., 108, 4642, doi:10.1029/2003JD003659, 2003.

Trautmann, T., Podgorny, I., Landgraf, J., and Crutzen, P. J.: Actinic fluxes and photodissociation coefficients in cloud fields embedded in realistic atmospheres, J. Geophys. Res., 104, 30173 30192, 1999.

Turco, R. P.: Photodissociation rates in the atmosphere below 100 km, Geophys. Surv., 2, 153-192, 1975.

Van Hoosier, M. E., Bartoe, J. D., Brueckner, G. E., and Printz, D. K.: Solar irradiance measurements 120-400nm from Space Lab2, IUGG Assembly, Vancouver, Canada, 1987.

Van Weele, M. and Duynkerke, P. G.: Effect of clouds on the photodissociation of $\mathrm{NO}_{2}$ : Observations and Modelling, J. Atmos. Chem., 16, 231-255, 1993.

Vilà-Guerau de Arellano, J., Duynkerke, P. G., and van Weele, M.: Tethered-balloon measurements of actinic flux in a cloud-capped marine boundary layer, J. Geophys. Res., 99(D2), 3699-3705, 1994.

Volz-Thomas, A., Lerner, A., Pätz, H. -W., Schultz, M., McKenna, D. S., Schmitt, R., Madronich, S., and Röth, E. P.: Airborne 
Measurements of the photolysis frequency of $\mathrm{NO}_{2}$, J. Geopys. Res., 101, 18613-18627, 1996.

Voulgarakis, A., Wild, O., Savage, N. H., Carver, G. D., and Pyle, J. A.: Clouds, photolysis and regional tropospheric ozone budgets, Atmos. Chem. Phys. 9, 8235-8246, doi:10.5194/acp-98235-2009, 2009.
Wild, O., Zhu, Z., and Prather, M. J.: Fast-J: Accurate simulation of in- and below-cloud photolysis in tropospheric chemical models, J. Atmos. Chem. 37, 245-282, 2000. 